\title{
Report from the 21st Annual Western Canadian Gastrointestinal Cancer Consensus Conference; Calgary, Alberta; 20-21 September 2019
}

\author{
Richard Lee-Ying ${ }^{1, *}$, Osama Ahmed $\left.{ }^{2}{ }^{(}\right)$, Shahid Ahmed ${ }^{2}{ }^{-}$, Shahida Ahmed ${ }^{3}$, Oliver F. Bathe ${ }^{4}$, Bryan Brunet ${ }^{2}$, \\ Laura Dawson $^{5}$, Janine Davies ${ }^{6}{ }^{(0)}$, Valerie Gordon ${ }^{3}$, Pamela Hebbard ${ }^{3}$, Jessica Kasnik ${ }^{7}$, Christina A. Kim ${ }^{3}{ }^{(1)}$, \\ Duc Le ${ }^{2}$, Michael K. C. Lee ${ }^{6}{ }^{\circledR}$, Howard Lim ${ }^{6}$, John Paul McGhie ${ }^{8}$, Karen Mulder ${ }^{7}$, Jason Park ${ }^{3}$, Daniel Renouf ${ }^{6}$, \\ Vincent Tam ${ }^{1}$, Robin Visser ${ }^{9}$, Ralph P. W. Wong ${ }^{3}$, Adnan Zaidi ${ }^{2}$ and Corinne Doll ${ }^{1}$
}

check for

updates

Citation: Lee-Ying, R.; Ahmed, O.; Ahmed, S.; Ahmed, S.; Bathe, O.F.; Brunet, B.; Dawson, L.; Davies, J.; Gordon, V.; Hebbard, P.; et al. Report from the 21st Annual Western Canadian Gastrointestinal Cancer Consensus Conference; Calgary, Alberta; 20-21 September 2019. Curr. Oncol. 2021, 28, 3629-3648. https:// doi.org/10.3390/curroncol28050310

Received: 26 August 2021

Accepted: 18 September 2021

Published: 21 September 2021

Publisher's Note: MDPI stays neutral with regard to jurisdictional claims in published maps and institutional affiliations.

Copyright: (c) 2021 by the authors. Licensee MDPI, Basel, Switzerland. This article is an open access article distributed under the terms and conditions of the Creative Commons Attribution (CC BY) license (https:/ / creativecommons.org/licenses/by/ $4.0 /)$.
1 Tom Baker Cancer Center, Alberta Health Service, Calgary, AB T2N 4N2, Canada; Vincent.tam@ahs.ca (V.T.); Corinne.Doll@albertahealthservices.ca (C.D.)

2 Saskatoon Cancer Center, Saskatchewan Cancer Agency, Saskatoon, SK S7N 4H4, Canada; Osama.Ahmed@saskcancer.ca (O.A.); Shahid.Ahmed@saskcancer.ca (S.A.); Bryan.Brunet@saskcancer.ca (B.B.); Duc.le@saskcancer.ca (D.L.); adnan.zaidi@saskcancer.ca (A.Z.)

3 Department of Oncology, Cancer Care Manitoba, Winnipeg, MB R3E 0V9, Canada; Shahida.Ahmed@saskcancer.ca (S.A.); vgordon1@cancercare.mb.ca (V.G.); Pamela.Hebbard@cancercare.mb.ca (P.H.); Ckim3@cancercare.mb.ca (C.A.K.); JPARK@sbgh.mb.ca (J.P.); ralph.wong@cancercare.mb.ca (R.P.W.W.)

4 Surgical Oncology, Arnie Charbonneau Cancer Institute, Calgary, AB T2N 4Z6, Canada; Oliver.Bathe@albertahealthservices.ca

5 Princess Margaret Cancer Centre, University Health Network, Toronto, ON M5G 2C1, Canada; Laura.Dawson@rmp.uhn.ca

6 Department of Oncology, British Columbia Cancer Agency, Vancouver, BC V5Z 4E6, Canada; jan.davies@bccancer.bc.ca (J.D.); MichaelKC.Lee@petermac.org (M.K.C.L.); hlim@bccancer.bc.ca (H.L.); drenouf@bccancer.bc.ca (D.R.)

7 Cross Cancer Institute, Alberta Health Services, Edmonton, AB T5G 1Z2, Canada; jessica.kasnik@ahs.ca (J.K.); Karen.Mulder@albertahealthservices.ca (K.M.)

8 Department of Oncology, British Columbia Cancer Agency, Victoria, BC V8R 4S1, Canada; jmcghie@bccancer.bc.ca

9 Department of Surgery, University of Manitoba, Winnipeg, MB R3E 0V9, Canada; rvisser@exchange.hsc.mb.ca

* Correspondence: richard.lee-ying@ahs.ca; Tel.: +1-403-521-3446

Abstract: The 21st annual Western Canadian Gastrointestinal Cancer Consensus Conference (WCGCCC) was held in Calgary, Alberta, 20-21 September 2019. The WCGCCC is an interactive multi-disciplinary conference attended by health care professionals from across Western Canada (British Columbia, Alberta, Saskatchewan, and Manitoba) involved in the care of patients with gastrointestinal cancer. Surgical, medical, and radiation oncologists, pathologists, radiologists, and allied health care professionals such as dietitians and nurses participated in presentation and discussion sessions to develop the recommendations presented here. This consensus statement addresses current issues in the management of hepato-pancreato-biliary (HPB) cancers.

Keywords: hepatocellular carcinoma; stereotactic body radiation therapy; pancreatic cancer; biliary tract cancer; cholangiocarcinoma; adjuvant chemotherapy; surgery

\section{Terms of Reference}

1.1. Purpose

The Western Canadian Gastrointestinal Cancer Consensus Conference (WCGCCC) aims to develop consensus opinion of oncologists and allied health professionals from across Western Canada, attempting to define best care practices and to improve care and outcomes for patients with gastrointestinal cancers. 


\subsection{Participants}

The WCGCCC welcomes medical oncologists, radiation oncologists, surgical oncologists, pathologists, radiologists, gastroenterologists, and allied health professionals from western Canada who are involved in the care of patients with gastrointestinal malignancies (Table 1).

Table 1. List of 2019 WCGCCC participants.

\begin{tabular}{|c|c|c|c|c|}
\hline Prefix & First Name & Last Name & Job Title & Organization \\
\hline Dr. & Shahid & Ahmed & Medical Oncologist & Saskatchewan Cancer Agency \\
\hline Dr. & Osama & Ahmed & Medical Oncologist & Saskatoon Cancer Centre \\
\hline Dr. & Oliver & Bathe & Professor & University of Calgary \\
\hline Dr. & Malcolm & Brigden & Medical Oncologist & Alberta Health Services \\
\hline Dr. & Bryan & Brunet & Radiation Oncologist & Saskatoon Cancer Center \\
\hline Dr. & Julianna & Caon & Radiation Oncologist & BC Cancer \\
\hline Dr. & Haji & Chalchal & Medical Oncologist & Allan Blair Cancer Ctr \\
\hline Dr. & Janine & Davies & Medical Oncologist & BC Cancer \\
\hline Dr. & Laura & Dawson & Professor & Princess Margaret Cancer Centre \\
\hline Dr. & Sonny & Dhalla & Surgeon & Brandon \\
\hline Dr. & Corinne & Doll & Radiation Oncologist & Tom Baker Cancer Centre \\
\hline Dr. & Abhijit & Ghose & Radiation Oncologist & Alberta Health Services \\
\hline Dr. & Sharlene & Gill & Medical Oncologist & BC Cancer \\
\hline Dr. & Kamal & Haider & MD & Saskatoon Cancer Centre \\
\hline Dr. & Edward & Hardy & Medical Oncologist & IHA/BC Cancer \\
\hline Mrs. & Eva & Hernandez & Registered Nurse & Cancer Care Manitoba \\
\hline Dr. & Michael & Humphreys & Medical Oncologist & BC Cancer \\
\hline Dr. & William & Hunter & Radiation Oncologist & CancerCare Manitoba \\
\hline Dr. & Will & Jiang & Resident (R5) & Tom Baker Cancer Centre \\
\hline Mrs. & Jessica & Kasnik & Dietitian & Cross Cancer Institute \\
\hline Dr. & Marc & Kerba & Radiation Oncologist & Tom Baker Cancer Centre \\
\hline Dr. & Christina & Kim & Medical Oncologist & CancerCare Manitoba \\
\hline Dr. & Sheryl & Koski & Medical Oncologist & Cross Cancer Institute \\
\hline Dr. & Marianne & Krahn & Medical Oncologist & CancerCare MB \\
\hline Dr. & Duc & Le & Radiation Oncologist & Saskatoon Cancer Centre \\
\hline Dr. & Michael & Lee & Medical Oncology Fellow & BC Cancer \\
\hline Dr. & Richard & Lee-Ying & Medical Oncologist & Tom Baker Cancer Centre \\
\hline Mrs. & Stephanie & Lelond & Clinical Nurse Specialist & CancerCare Manitoba \\
\hline Dr. & Howard & Lim & Medical Oncologist & BC Cancer \\
\hline Dr. & Hongwei & Liu & Radiation Oncologist & Central Alberta Cancer Center \\
\hline Dr. & Shaun & Loewen & Radiation Oncologist & Tom Baker Cancer Centre \\
\hline Dr. & Shazia & Mahmood & Radiation Oncologist & Saskatchewan Cancer Agency \\
\hline Dr. & Simon & Mairs & Medical Oncologist & Alberta Health Services \\
\hline Dr. & Karen & Mulder & Medical Oncologist & Cross Cancer Institute \\
\hline Dr. & Kim & Paulson & Radiation Oncologist & University of Alberta \\
\hline Ms. & Carla & Pires Amaro & Medical Oncology Fellow & Tom Baker Cancer Centre \\
\hline Mrs. & Elvira & Planincic & Registered Nurse & Cancer Care Manitoba \\
\hline Mrs. & Kimberly & Robins & Pharmacist & CancerCare Manitoba \\
\hline Dr. & Diane & Severin & Radiation Oncologist & Cross Cancer Institute \\
\hline Dr. & John & Shaw & HPB Surgeon & Royal University Hospital \\
\hline Dr. & Rishi & Sinha & Radiation Oncologist & Tom Baker Cancer Centre \\
\hline Ms. & Karen & Stolz & Registered Nurse & Cancer Care Manitoba \\
\hline Dr. & Amina & Taleb & Medical Oncology Fellow & Tom Baker Cancer Centre \\
\hline Dr. & Vincent & Tam & Medical Oncologist & Tom Baker Cancer Centre \\
\hline Dr. & Keith & Tankel & Radiation Oncologist & Cross Cancer Institute \\
\hline Ms. & Kathy & Trakalo & Research Nurse & CancerCare Manitoba \\
\hline Dr. & Robin & Visser & Hepatobiliary Surgery & Health Sciences Center \\
\hline Dr. & Ralph & Wong & Medical Oncologist & Cancercare Manitoba \\
\hline Dr. & Nobby & Woo & General Surgeon & University of Manitoba \\
\hline Dr. & David & $\mathrm{Wu}$ & Radiation Oncology R4 & Tom Baker Cancer Centre \\
\hline Dr. & Adnan & Zaidi & Medical Oncologist & Saskatchewan Cancer Agency \\
\hline Dr. & Muhammad & Zulfiqar & Medical Oncologist & BC Cancer \\
\hline
\end{tabular}




\subsection{Target Audience}

The recommendations presented here are targeted at health care professionals involved in the care of patients with hepato-pancreato-biliary (HPB) cancers.

\subsection{Basis of Recommendations}

The recommendations are based on the presentation and discussion of the best available evidence. Where applicable, references are cited. Additional evidence has been published since the timing of the 2019 meeting, and the authors have incorporated this, where relevant, into each topic discussion. Barriers to access (e.g., approval but no funding) and limitations in data interpretation continue to make the consensus recommendations relevant, even in light of new data.

\section{Question 1}

What is the current role of stereotactic body radiation (SBRT) in hepatocellular carcinoma (HCC)?

\subsection{Recommendations}

The role of SBRT in HCC is evolving and clinical trials should always be considered. Cases should be reviewed in multi-disciplinary rounds. SBRT is an option to be considered alongside other ablative therapies. SBRT as a bridge or downstaging to transplant could also be considered in addition to other local regional strategies.

\subsection{Summary of Evidence}

The role of SBRT continues to be refined, with clinical trial enrollment as the optimal means of advancing its use in HCC. When considered alongside other ablative therapies in a multi-disciplinary discussion, SBRT is best suited for patients with HCC at a higher risk of complications or recurrence following interventional ablative therapies (e.g., tumors $>3-5 \mathrm{~cm}$, infiltrative tumors, located near the dome of the liver) [1]. SBRT can also serve as a bridge to or as downsizing for transplant in addition to other local regional strategies. Risks are higher in patients who receive SBRT for central lesions and who go on to have a live donor liver transplant. Thus, multi-disciplinary decision making is crucial for these patients.

Vascular invasion is a poor prognostic factor in HCC patients. Survival is worse in patients with more extensive HCC with vascular involvement (main vessel involvement, occlusive tumor thrombus). For patients with vascular invasion (hepatic vein, portal vein, IVC or branch invasion), SBRT may be used with the goal of debulking or ablating intravascular tumor and increasing the chance of recanalization. A randomized phase II study from Korea demonstrated improved progression free survival (PFS) and overall survival (OS) with radiation therapy combined with TACE compared to sorafenib alone, in patients with macrovascular HCC invasion [2].

\section{Question 2}

What is the optimal sequence of systemic therapy in patients with advanced HCC? In the first line setting? In the second line setting?

\subsection{Recommendations}

- Sorafenib or lenvatinib are options for first line therapy in patients who are not eligible for local-regional strategies and have a Child-Pugh A score. Sorafenib can also be considered in Child-Pugh B7 in the absence of ascites. The alternate treatment can be considered in cases of intolerance.

- In the second line setting, options include regorafenib and cabozantinib.

- Clinical trials should be considered. The role of immunotherapy is evolving. 


\subsection{Summary of Evidence}

Sorafenib has been the standard treatment for advanced HCC for over a decade since the SHARP and Asia-Pacific trials showed that sorafenib improved OS compared to placebo [3,4]. In 2018, the REFLECT trial showed that lenvatinib is non-inferior for OS when compared to sorafenib in the first-line treatment of advanced HCC [5]. Response rates and PFS favored lenvatinib. The patients included in these trials had Child-Pugh A liver function. For patients with Child-Pugh B liver function, sorafenib appears to be safe according to the GIDEON observational study [6]. Many oncologists would treat patients with Child-Pugh B7 liver dysfunction in the absence of ascites if the patient has a good performance status.

In clinical trials, sorafenib has been shown to be associated with toxicities such as palmar-plantar erythrodysesthesia, diarrhea, hypertension, anorexia, weight loss and fatigue [3,4]. Lenvatinib appears to have lower rates of palmar-plantar erythrodysesthesia, but higher rates of hypertension [5]. Thus, in patients intolerant of sorafenib for such toxicities as palmar-plantar erythrodysesthesia, lenvatinib should be considered. Alternatively, in patients with poorly controlled hypertension, sorafenib would be preferred. Other first-line treatment options, such as the combination of atezolizumab and bevacizumab were not available at the time of this discussion.

In second line setting, post-sorafenib, the RESORCE trial found that regorafenib improves OS compared to placebo (median 10.6 vs. 7.8 months, HR $0.63,95 \%$ CI $0.50-0.79$, $p<0.0001)$. Patients in this study must have tolerated and progressed on sorafenib [7]. In 2018, the CELESTIAL trial found that cabozantinib improves OS compared to placebo (median 10.2 vs. 8.0 months, HR $0.7695 \%$ CI $0.63-0.92, p=0.005$ ) when given to patients who have been treated with up to two lines of systemic therapy for hepatocellular carcinoma, including previous treatment with sorafenib [8]. The REACH-2 trial evaluated patients after first-line sorafenib with a poorer prognosis with an AFP $\geq 400 \mathrm{ng} / \mathrm{mL}$, and found that ramucirumab led to a more modest improvement in OS compared to placebo (median 8.5 vs. 7.3 months, HR $0.710,95 \%$ CI $0.531-0.949, p=0.0199$ ), which though statistically significant may not be as clinically significant [9].

The prognosis of advanced stage HCC is still very poor despite the recent advances in systemic treatment. Immunotherapy drugs are currently being studied in clinical trials. However, two reported phase III trials of anti-PD1 drug monotherapy (nivolumab, pembrolizumab) have failed to show a statistically significant improvement in overall survival in first- and second-line treatment, respectively, despite previous accelerated FDA conditional approval $[10,11]$. Trials of combination treatments including immunotherapy and tyrosine-kinase inhibitors in the first-line setting for advanced HCC are ongoing. The combination of atezolizumab and bevacizumab, compared to sorafenib in the IMbrave150 study, presented at ESMO Asia 2019, after the WCGCCC meeting, suggests that the combination is superior to sorafenib and likely to become a new standard of care in the first line setting [12]. The combination of atezolizumab and bevacizumab is Health Canada approved and received a conditional approval from the national oncology-specific health technology assessment body pan-Canadian Oncology Drug Review (pCODR) assuming the cost-effectiveness of the treatment can be improved upon [13]. Despite support for its use, funding negotiations remain unresolved, limiting its use to a minority of patients who can afford to pay out of pocket or with the assistance of a private drug plan. Patients with a history of autoimmune disease or uncontrolled varices are also ineligible, keeping discussions about lenvatinib and sorafenib in the first-line setting relevant.

Existing second line studies all used sorafenib as a first line treatment, so it is difficult to interpret the efficacy of these novel agents in the context of new data. The RESORCE trial excluded patients who had other systemic treatments beyond sorafenib, while the CELESTIAL trial included patients with two or more systemic therapies, including 17 patients who had prior immunotherapy, though not specifically in the combination of atezolizumab and bevacizumab $[7,8]$. Further expert opinion and limited real-world studies have suggested that the activity of sorafenib and lenvatinib, post-atezolizumab and bevacizumab may 
have similar activity to the first line setting, suggesting a simple shift in the sequencing discussed at the 2019 WCGCCC meeting $[14,15]$.

\section{Question 3}

What are the important dietary interventions in the management of pancreatic cancer? What is the role of pancreatic enzyme replacement therapy?

\subsection{Recommendations}

All patients with pancreas cancer should be referred to a registered dietitian for specialized nutritional care due to the high risk of malnutrition. Initial care providers should screen patients for pancreatic enzyme deficiency and initiate replacement if needed.

\subsection{Summary of the Evidence}

Pancreatic cancer is a very aggressive malignancy that is often not diagnosed until an advanced or metastatic stage. More than $80 \%$ of patients with PDAC present with malnutrition at diagnosis due to multifactorial causes $[16,17]$. It has been estimated that $10-20 \%$ of deaths in patients with cancer are related to malnutrition rather than their malignancy [18]. Therefore, it is essential to identify, understand the etiology, and apply appropriate nutritional interventions to curtail the deleterious symptoms of malnutrition and improve clinical outcomes. The three factors which expose pancreatic cancer patients to such a high risk of malnutrition are (1) disease-related malnutrition (anorexia, hypermetabolism), (2) treatment side effects (nausea, vomiting, constipation, diarrhea, mouth sores, taste changes), and (3) exocrine/endocrine dysfunction. A consultation with a specialized registered dietitian can support the patient and team in the identification and management of these issues.

In the setting of cancer, both pancreatic exocrine and endocrine functions can be affected. Endocrine cells make up approximately $5 \%$ of the pancreas and function to regulate metabolism in the body through the production and secretion of hormones such as insulin and glucagon. Derangements in this system will present as diabetes mellitus [18]. The majority of pancreatic cells, however, are exocrine cells. The pancreatic exocrine cells produce digestive juices (bicarbonate) and enzymes (protease, amylase, and lipase) which are essential for the neutralization of gastric chyme and the digestion of all macronutrients. Pancreatic enzyme insufficiency (PEI) is defined as the reduced or inappropriate secretion or activity of pancreatic juice and its digestive enzymes, particularly pancreatic lipase. The presence of PEI affects a patients' ability to properly digest and absorb protein (protease), fat (lipase), and complex carbohydrates (amylase).

When assessing this population for PEI, it is important to consider location, size, history of chronic pancreatitis, ductal obstruction and surgical intervention to the pancreas and tumor. The prevalence of PEI post Whipple procedure is $80-90 \%$ compared to $20-50 \%$ in patients who underwent a distal pancreatectomy. In contrast, $20-60 \%$ of patients with unresectable pancreatic adenocarcinoma have PEI [19].

Signs and symptoms of PEI can be broken down into three main categories; abdominal, nutritional and endocrine. Abdominal symptoms include diarrhea, steatorrhea, fecal urgency, bloating, malodorous gas, GERD, cramping and abdominal pain, and post prandial gurgling. Nutritional symptoms include weight loss, sarcopenia, weakness and fatigue, food avoidance, and fat soluble vitamin deficiency. Endocrine symptoms will present with hypoglycemia or decreased hyperglycemic agent requirements. If a patient has pancreatic adenocarcinoma and any of the above symptoms, the intervention recommended is pancreatic enzyme replacement therapy (PERT) $[19,20]$. Patients who have an intact stomach taking enzymes orally require enterically coated versions. The two main brands of these enzymes used in Canada are Creon 10 and 25 and Cotazym ECS 8 and 20. Non-enterically coated enzymes (Viokase, Cotazym) are required for patients with a feeding tube (gastrically or jejunely) or post-gastrectomy. Each capsule of PERT has a combination of protease, lipase and amylase, as broken down in Table 2. 
Table 2. Breakdown of pancreatic enzyme replacement therapy components.

\begin{tabular}{cccc}
\hline Enzyme & Lipase & Protease & Amylase \\
\hline Cotazym ECS 8 & 10,800 & 45,000 & 42,000 \\
\hline Cotazym ECS 20 & 25,000 & 100,000 & 100,000 \\
\hline Creon 10 & 10,000 & 790 & 11,200 \\
\hline Creon 25 & 25,000 & 1600 & 25,500 \\
\hline Cotzym * & 10,000 & 35,000 & 40,000 \\
\hline Viokace 20 880 * & 20,880 & 112,500 & 113,400 \\
\hline non-enteric PERT. & & &
\end{tabular}

*non-enteric PERT.

The dosing of PERT is primarily based on the cystic fibrosis population and additional enzyme replacement is likely needed for the pancreatic cancer population [16]. PERT is prescribed based on per kilogram body weight of the patient, in a range of 500-2500 units of lipase per kilogram body weight per meal, up to 10000 units of lipase per kilogram of body weight per day. The risk associated with exceeding this is constipation. PERT should be taken before all meals and snacks that contain macronutrients and will last for up to $1 \mathrm{~h}$ after consumption. Larger meals or meals that contain a higher amount of fat will require more PERT for adequate digestion.

The European Society for Clinical Nutrition and Metabolism (ESPEN) and the American Society for Parenteral and Enteral Nutrition (ASPEN) guidelines suggest no macronutrient restriction, with protein requirements elevated to $1.2-2.0 \mathrm{~g} / \mathrm{kilogram}$ body weight/day. Patients on appropriate PERT should feel an improvement in symptom burden and will better absorb the nutrients they are ingesting.

\section{Question 4}

What is the optimal neoadjuvant/adjuvant strategy for pancreas cancer?

\subsection{Recommendations}

- Six months of mFOLFIRINOX is standard adjuvant therapy for patients with resected pancreatic cancer. In patients who are not candidates for mFOLFIRINOX, a combination of gemcitabine/capecitabine or gemcitabine alone or 5FU alone can be considered.

- The role of adjuvant radiation is not well defined but may be considered in patients with high risk of local recurrence, in the context of a multidisciplinary discussion.

- Cases should be reviewed in a multi-disciplinary fashion to determine the intent and strategy for borderline resectable pancreas cancer. Clinical trials should be considered for these patients. Neoadjuvant chemotherapy using FOLFIRINOX is the preferred strategy. Gemcitabine and Nab-paclitaxel can be considered depending on patient factors and tolerability. Chemoradiotherapy or radiotherapy could be considered in select cases.

- In resectable cases, there is no evidence-based role for neoadjuvant chemotherapy to date; clinical trials should be considered.

\subsection{Summary of Evidence}

Pancreatic ductal adenocarcinoma (PDAC) is an aggressive cancer, and only approximately $20 \%$ of cases present when disease is localized and amenable to surgical resection [21]. Various trials have assessed the impact of adjuvant therapy after surgical resection of PDAC. The ESPAC-1 study was a two-by-two factorial design, randomizing patients to adjuvant chemoradiation, chemotherapy, both treatments or observation alone, with a goal of assessing the impact of chemoradiation versus no chemoradiation, and chemotherapy versus no chemotherapy on two-year OS [22]. Accrual was poor, therefore patients were accrued in a parallel study known as ESPAC-1 plus, where they were ran- 
domized to adjuvant chemotherapy with bolus 5-fluorouracil (5FU) and folinic acid versus observation, and clinicians were able to provide chemoradiotherapy if they felt that it was clinically indicated [23]. Overall, the results of ESPAC-1 showed a benefit to adjuvant chemotherapy, with a two-year OS of $40 \%$ with chemotherapy compared to $30 \%$ with no chemotherapy, and possible harm to the administration of adjuvant chemoradiation, with a two-year OS of $29 \%$ with chemoradiation compared to $41 \%$ amongst those who received no chemoradiation. ESPAC-1 was not powered to assess the impact of adjuvant chemotherapy to observation, however, the ESPAC-1 plus results showed a similar benefit to adjuvant chemotherapy. The interpretation of these studies is limited by a number of factors, including the complicated study design and radiation techniques used.

However, further trials demonstrated the utility of adjuvant chemotherapy in resectable PDAC. The CONKO-001 trial randomized patients who had undergone a complete macroscopic resection to six cycles of gemcitabine $1000 \mathrm{mg} / \mathrm{m}^{2}$ on days 1,8 and 15 of a 28 -day cycle or observation [24,25]. There was a statistically significant improvement in disease free survival (DFS) (median DFS 13.4 months with gemcitabine versus 6.7 months with observation) and OS (5-year OS $20.7 \%$ with gemcitabine versus $10.4 \%$ with observation), and this benefit persisted in patients with both $\mathrm{R} 0$ and $\mathrm{R} 1$ resections. A randomized comparison of adjuvant gemcitabine to 5FU showed no difference in OS, however, there was more grade 3 toxicity, including stomatitis, diarrhea and hospitalizations, with 5FU compared to gemcitabine [26].

The ESPAC-4 study addressed whether six months adjuvant gemcitabine and capecitabine, was superior to gemcitabine alone [27]. Patients with macroscopically complete resection of PDAC, with no evidence of metastatic disease, an Eastern Cooperative Group (ECOG) performance score (PS) of 0-2, who had not received any neoadjuvant chemotherapy, were randomized to combination therapy with gemcitabine $1000 \mathrm{mg} / \mathrm{m}^{2}$ weekly on days 1, 8 and 15 of a 28 day cycle and capecitabine $1660 \mathrm{mg} / \mathrm{m}^{2}$ for 21 days followed by a 7 day break, versus gemcitabine alone. Results were stratified by country of enrollment and resection margin status (R0 versus R1). Treatment was to be started within 12 weeks of surgery and enrollment in ESPAC-4 was not restricted by post-operative CA 19-9 levels. The primary endpoint was OS and secondary endpoints included survival at 24 months and 5 years, relapse free survival (RFS), toxicity and quality of life as measured by the EORTC QLQ-C30 questionnaire. The study cohort included patients with a poor prognosis, as $60 \%$ of patients had R1 resection margins, $80 \%$ had lymph node positive disease, and post-operative CA 19-9 levels ranged from 0.1 to $>8000$. The median OS with gemcitabine and capecitabine was 28.0 months compared to 25.5 months with gemcitabine alone (hazard ratio $0.82,95 \%$ CI $0.68-0.98, p=0.032$ ). On multivariable analysis, tumor grade, lymph node status, maximum tumor size, resection margin status and post-operative CA 19-9 levels were independent predictors of OS. Interestingly, there was no difference in RFS between combination therapy and gemcitabine alone (HR 0.86, 95\% CI 0.73-1.02, $p=0.082$ ). There was increased grades 3 and 4 toxicity with combination therapy, including increased neutropenia, infections, diarrhea and hand foot syndrome.

APACT is a phase III randomized controlled trial assessing adjuvant nab-paclitaxel plus gemcitabine (NG) compared to gemcitabine alone, with a primary endpoint of independently assessed DFS [28]. Patients with resected PDAC with no evidence of metastatic disease and a post-operative CA 19-9 < 100 were randomized in a 1:1 fashion to the two treatment arms. Results were stratified by geographic region, resection margin status and lymph node status. In total, $24 \%$ of patients had R1 margins and $72 \%$ had lymph node positive disease. There was no difference in independently assessed DFS between the two treatment groups. The median DFS with NG was 19.4 months, compared to 18.8 months with gemcitabine alone (hazard ratio $0.88,95 \%$ CI $0.73-1.06, p=0.18$ ). In a pre-planned subgroup analysis, the groups that appeared to benefit from combination therapy included moderate compared to poorly differentiated tumors, lymph node positive disease and normal CA 19-9. There was a statistically significant difference in investigator-assessed DFS, at 16.6 months for NG, compared to 13.7 months for gemcitabine (hazard ratio 0.82, 95\% 
CI $0.694-0.965, p=0.0168)$. The difference between independent and investigator assessed DFS may be related to the clinical features that physicians take into consideration, alongside radiologic findings, when assessing disease progression in patients with PDAC. The median OS for those who received NG was 40.5 months, compared to 36.2 months for gemcitabine alone (hazard ratio $0.82,95 \%$ CI $0.68-0.996, p=0.045$ ), although data are not yet mature.

Investigation of a more intensive adjuvant regimen was investigated in the PA.6 trial [29]. Patients with macroscopic resection of PDAC, with no evidence of metastatic disease were randomized to six months of modified FOLFIRINOX (mFOLFIRINOX), consisting of $46 \mathrm{~h}$ infusion of $5 \mathrm{FU}\left(2400 \mathrm{mg} / \mathrm{m}^{2}\right)$, leucovorin $\left(400 \mathrm{mg} / \mathrm{m}^{2}\right)$, oxaliplatin $\left(85 \mathrm{mg} / \mathrm{m}^{2}\right)$ and irinotecan $\left(150 \mathrm{mg} / \mathrm{m}^{2}\right)$ given once every two weeks, or gemcitabine $1000 \mathrm{mg} / \mathrm{m}^{2}$ given on days 1,8 and 15 on a 28 day schedule. Criteria for enrollment in this study were more stringent, as patients had to be $<79$ years old, have an ECOG PS of $0-1$, with a bilirubin level $<1.5$ times the upper limit of normal, a creatinine clearance of $>50 \mathrm{~mL} /$ minute, and a post-operative CA $19-9$ level $<180$. The primary endpoint was DFS and other endpoints included OS and safety. Results were stratified by trial center, nodal status, margin status and post-operative CA 19-9 levels. With this stricter inclusion criteria, approximately $40 \%$ of patients had R1 resections, $73 \%$ had stage IIB disease, and $0.4 \%$ had stage III disease. The median DFS with mFOLFIRINOX was 21.6 months, compared to 12.8 months with gemcitabine (stratified hazard ratio $0.58,95 \% \mathrm{CI} 0.46-0.73, p<0.001$ ). This benefit with mFOLFIRINOX was seen in all subgroups, including those with T3/4 tumors, $\mathrm{N} 1$ disease and R1 resections. In an exploratory subgroup analysis of patients $>70$ years old, representing $20.5 \%$ of the study population, the benefit of mFOLFIRINOX over gemcitabine did not reach significance (hazard ratio $0.86,95 \% \mathrm{CI}, 0.53-1.39$ ). On multivariable analysis, factors independently predictors of worse DFS included tumor grade and portal vein resection. Median OS was also improved with mFOLFIRINOX at 54.5 months compared to 35.0 months with gemcitabine (stratified hazard ratio for death, $0.64 ; 95 \%$ CI, $0.48-0.86$; $p=0.003$ ). It should be noted that the median OS seen in the gemcitabine group is longer than what has been seen historically, with many potential reasons, including better surgical technique, patient selection and post-progression therapies. As expected, mFOLFIRINOX was associated with increased toxicity. Grade 3/4 toxicity occurred in $52.9 \%$ of patients receiving mFOLFIRINOX, compared to $12.2 \%$ of those receiving gemcitabine. Specifically, there was more mucositis, nausea, vomiting, diarrhea, abdominal pain, fatigue, elevated GGT and paresthesias with mFOFLIRINOX. Over $60 \%$ of those receiving mFOLFIRINOX received growth factor support, compared to $3.7 \%$ of those receiving gemcitabine. There was no difference in grade $3 / 4$ toxicity based on age $<70$ or $>70$. Due to the superior survival seen with mFOLFIRINOX, it is the adjuvant chemotherapy regimen of choice; however, factors such as age, ECOG PS, comorbidities, post-operative CA 19-9 and chemotherapy toxicity profile should be taken into consideration.

The role of adjuvant radiation is not well defined and results from randomized trials are conflicting. Overall, there is no strong evidence for using radiation therapy for a survival improvement. Adjuvant radiation therapy may be considered in selected patients, following systemic therapy, with the primary goal of reducing the risk of local-regional recurrence and maintaining quality of life. In resectable cases, there is no evidence for the routine use of neoadjuvant radiation therapy [30]. When radiation therapy is used for the treatment of pancreatic cancer, pre-radiation treatment anti-emetics are recommended. For patients with tumors close to the stomach or duodenum (the great majority of pancreatic cancers), proton pump inhibitors are recommended to reduce the risk of gastric toxicity [30].

When deciding on whether a neoadjuvant approach or an upfront surgical approach should be taken, it is critical to clearly define whether a PDAC is resectable, borderline resectable, borderline unresectable or unresectable. Definitions of resectability have evolved over time and require sufficient radiographic and surgical expertise to determine. The nature and extent of vascular involvement is often a primary determinant of resectability, with abutment indicating $\leq 180$ degree involvement and encasement $>180$ degree involvement of a particular vessel. To be considered borderline resectable, most guidelines permit 
superior mesenteric vein/portal vein encasement, as long as reconstruction of the vessel is feasible, while the superior mesenteric artery can typically only have abutment for a case to be considered borderline resectable [31-36]. Borderline resectable cases typically permit common hepatic artery abutment or short-segment encasement, while most guidelines indicate celiac artery abutment or encasement would render pancreatic cancer unresectable [31-36]. Notably, there can be exceptions to arterial involvement, as arterial replacement or resections can occasionally be performed by an experienced hepatobiliary surgeon. Given the complexity of the determination, it often falls to the hepatobiliary surgeon with or without a multidisciplinary discussion to elucidate what is safe and feasible. Clear communication is important to set patient and provider expectations, particularly when disease is either unresectable or only borderline resectable so that management plans can be appropriately aligned with realistic goals.

The role of neoadjuvant chemotherapy in patients with resectable disease is unclear. Offering chemotherapy up front in patients with disease that is amenable to surgical resection may offer some benefits. Neoadjuvant treatment may allow for an assessment of tumor biology, including an evaluation of whether disease responds to aggressive chemotherapy. Those with progressive disease despite optimal chemotherapy may be spared from an aggressive and potentially morbid surgery. Giving neoadjuvant chemotherapy has the potential to treat micrometastatic disease and increase R0 resections. Due to the potential for post-operative complications, which may delay or limit the ability to administer adjuvant chemotherapy, giving chemotherapy before surgery may be preferred. Despite these potential benefits, the role of neoadjuvant chemotherapy in patients with resectable PDAC remains unclear, as there is a lack of evidence to support such an approach. A systematic review and meta-analysis attempted to address this question [37]. When including only randomized and prospective phase II and III trials comparing neoadjuvant to adjuvant therapy, only two phase II papers, one of which was randomized, were identified. The inclusion criteria were therefore expanded to include an additional four prospective and three retrospective studies. The analysis favored neoadjuvant therapy for increasing R0 resections and survival at various time points, however, the poor quality and small number of studies limits the ability to make strong conclusions about the role of neoadjuvant therapy in this setting, and ultimately, upfront surgery followed by adjuvant chemotherapy remains the standard of care for patients with resectable PDAC. Ongoing trials, such as the NEOPAC (NCT01521702) and ALLIANCE A021806 studies, will add further information about the role of neoadjuvant therapy for PDAC. One of the challenges of trials in this setting will be to ensure clear definitions of resectable disease and confirming trial participants are indeed eligible [38], and the endpoints chosen in trials should reflect clinically relevant endpoints including OS and $\mathrm{R} 0$ resection rates.

The role of neoadjuvant chemotherapy in borderline resectable PDAC is also unclear. In a phase 2 study of 48 patients with borderline resectable PDAC determined by a multidisciplinary team review, patients received pre-operative FOLFIRINOX followed by neoadjuvant chemoradiation [39]. The primary outcome was $\mathrm{R} 0$ resection rate, which was achieved in $65 \%$ of patients. The median PFS was 14.7 months and the median OS was 37.7 months. A meta-analysis compared the impact of neoadjuvant therapy (chemotherapy, chemoradiation or both) versus upfront surgery on survival in patients with resectable or borderline resectable PDAC [40]. The median OS with any neoadjuvant therapy was 18.8 months, compared to 14.8 months for those who underwent upfront surgery. A retrospective study of patients with borderline resectable and locally advanced PDAC receiving neoadjuvant FOLFIRINOX versus upfront surgery showed that $92 \%$ of patients had an R0 resection who received neoadjuvant FOLFIRINOX [41]. Given the heterogeneity of the populations included in these studies (resectable, borderline resectable and locally advanced disease), as well as the heterogeneity of the neoadjuvant therapies used, one should be cautious when interpreting these results. Ultimately, clear definitions of resectability and well-designed randomized phase 3 trials are required to answer the question of the role of neoadjuvant chemotherapy, and the optimal regimen, in borderline resectable PDAC. 
Currently, if patients are to receive neoadjuvant therapy for PDAC, this would best be done on a clinical trial. Cases should be reviewed in a multi-disciplinary fashion to determine the intent and strategy for borderline resectable pancreas cancer as it is important to set realistic expectations for patient outcomes. Neoadjuvant chemotherapy using FOLFIRINOX is the preferred strategy due to its objective response rate $(31.6 \%)$ in the metastatic setting and efficacy in the adjuvant setting [29,42]. Notably, an objective response may not translate to conversion from borderline resectable to resectable disease, as there may be specific anatomic considerations required for a response to allow for surgical resectability. NG can be considered depending on patient factors and tolerability, though it does have a lower objective response rate $(23 \%)$ in the metastatic setting and more questionable benefit in the adjuvant setting $[28,43]$. Chemoradiotherapy or radiotherapy alone may be considered in selected cases following systemic therapy. The primary role of radiation therapy is to increase the chance of a $\mathrm{R} 0$ resection margin and to reduce the risk of local recurrence. Capecitabine is the preferred radiation sensitizer for patients who have previously received FOLFIRINOX, and it has been shown to be associated with less toxicity than gemcitabine-based chemo-radiation therapy [44]. Gemcitabine-based chemo-radiation therapy is an alternative for patients who have not received FORFIRINOX.

Published after the WCGCCC meeting, the PREOPANC trial randomized patients with resectable and borderline resectable pancreatic cancer to receive chemoradiation with gemcitabine and surgery or surgery alone, followed by adjuvant gemcitabine [45]. This trial demonstrated an improvement in surrogate endpoints such as R0 resection rates (71 vs. $40 \%$ ), disease-free survival and locoregional failure-free interval with the use of neoadjuvant chemoradiation. No OS benefit was observed initially, though with longer follow-up a potential survival benefit has been suggested $[45,46]$. However, this trial utilizes inferior systemic treatment in the control arm with gemcitabine alone and may not be reflective of modern practice. The phase II SWOG S1505 study compared neoadjvuant treatment with mFOLFIRINOX and nab-pacltaxel/gemcitabine and found similar R0 resection rates (73 vs. $70 \%$ ) but failed to meet pre-specified endpoints to be carried forward [47]. The results from further trials such as PREOPANC II, using FOLFIRINOX are awaited [48]. Despite new data since the WCGCCC meeting, routine use of neoadjuvant treatment remains an area of active research, and there remains a need for better powered studies to determine who best to adopt a neoadjvuant approach for.

\section{Question 5}

What are the current standard surgical options for patients with hepatocellular carcinoma?

\subsection{Recommendations}

- Patients should be referred to a hepatobiliary surgeon to review local regional strategies and for multi-disciplinary review. Multi-disciplinary review should involve representatives from transplant, surgery, radiation oncology, medical oncology and interventional radiology. Surgery remains the gold standard for resectable HCC if able to obtain an adequate future liver remnant (FLR). Transplantation is preferred for non-resectable HCC patients with cirrhosis within transplant criteria.

\subsection{Summary of Evidence}

Over recent years there have been significant technological and scientific developments related to the treatment of hepatocellular carcinoma. As a result, there are more locoregional treatment options as well as systemic treatment options. Locoregional treatment options include resection, including laparoscopic resection, liver transplantation, thermal ablation (including radiofrequency ablation and microwave ablation), stereotactic body radiotherapy (SBRT), transarterial chemoembolization (TACE), brachytherapy (where available), and transarterial radioembolization (TARE). The nuances of each of these therapeutic modalities, including case-specific feasibility, limitations and precautions, 
require expert input from specialists from different disciplines. Therefore, an effective multidisciplinary discussion requires the involvement of surgeons, hepatologists, interventional radiologists, radiation oncologists and medical oncologists, as well as diagnostic radiologists.

The diagnosis of HCC is often made based on imaging, without a biopsy. The Liver Imaging Reporting and Data System (LI-RAD) classification of liver lesions enables estimation of the likelihood that a liver lesion is a hepatocellular carcinoma [49]. Expert assessment of liver lesions by a radiologist is therefore integral to clinical management.

Decisions related to the optimal management of hepatocellular carcinoma require a full appreciation of the patient's comorbidities and performance status, as well as an assessment for underlying liver disease and portal hypertension. A full medical evaluation is essential. Liver function is first evaluated by applying Child-Pugh criteria [50], which requires INR, albumin, total bilirubin, and evaluation for ascites and encephalopathy. If transplantation is being considered, the MELD score can be calculated (based on creatinine, bilirubin, INR and serum sodium) [51]. Good renal function is essential for TACE. If it is unclear whether hepatic fibrosis or cirrhosis is present, ultrasound elastography or MR elastography is helpful [52]. The presence of portal hypertension can be deduced if varices are seen on cross-sectional imaging or esophagogastroscopy, or if there is evidence of hypersplenism such as a large spleen or thrombocytopenia.

Anatomic factors must also be considered. The intent of resection is curative and therefore, it must be feasible to remove the entirety of the tumor while leaving sufficient liver remnant to avoid liver failure. Occasionally, it may be necessary to perform a portal vein embolization on the side that is being removed in order to induce hepatic hypertrophy on the liver remnant. Thermal ablation should be avoided in lesions located centrally, near the bifurcation of the porta hepatis; lesions located near large vessels are susceptible to heat sink [53], limiting the effectiveness of the procedure; accessing lesions at the liver surface should consider the approach due potential risks of tumor seeding. While transplantation is the best option for healthy patients with poor liver function, it is not indicated in the presence of a large tumor burden. The Milan criteria (a solitary lesion $\leq 5 \mathrm{~cm}$ maximal diameter or up to 3 lesions $\leq 3 \mathrm{~cm}$ ) [54] represent conservative criteria, but extended criteria have been more recently introduced with acceptable results $[55,56]$.

The Barcelona Clinic Liver Cancer (BCLC) staging system represents one construct that can help to guide treatment options [57]. The BCLC staging system takes into account the Child-Pugh grade of liver function, the size and number of nodules, and performance status (Table 3). In addition, the platelet count should be considered in treatment decisions. The optimal candidate for resection is an individual who is in good medical condition, has good performance status, has good hepatic functional reserve (Child-Pugh A), has a normal platelet count and has no varices. This corresponds to patients in BCLC Stage 0 or A. Having said that, as described above, there are many nuances to decision-making, and alternatives to resection could also be considered. While the BCLC staging system is an excellent construct to help make treatment decisions, it must be appreciated that there are numerous treatment options for each BCLC stage. The best options are a product of local expertise, and they will evolve as the clinical science improves. 
Table 3. Criteria for the Barcelona Clinic Liver Cancer (BCLC) staging system.

\begin{tabular}{cccc}
\hline BCLC Stage & Tumor Stage & Child-Pugh Class & ECOG Performance Status \\
\hline Very Early (0) & Single $\leq 2 \mathrm{~cm}$ & A & 0 \\
\hline Early (A) & $\begin{array}{c}\text { Single } \leq 5 \mathrm{~cm} \\
\text { Up to } 3 \text { lesions } \leq 3 \mathrm{~cm}\end{array}$ & A, B & 0 \\
\hline Intermediate (B) & Multifocal & A, B & $1-2$ \\
Advanced (C) & $\begin{array}{c}\text { Portal Vein Invasion } \\
\text { Lymph Node Involvement } \\
\text { M1 disease }\end{array}$ & A & $\geq 3$ \\
\hline End Stage (D) & Any & C & \\
\hline
\end{tabular}

\section{Question 6}

What is the standard second line treatment option in patients with advanced pancreatic cancer? What is the role of targeted treatments for advanced pancreatic cancer?

\subsection{Recommendations}

- $\quad$ Post-FOLFIRINOX, second line gemcitabine + nab-paclitaxel is the preferred regimen. Gemcitabine alone can also be considered in patients not able to tolerate the combination.

- Post nab-paclitaxel + gemcitabine, nanoliposomal irinotecan +5FU or OFF are preferred regimens.

- For MSI-high, MMR-deficient pancreatic cancer, pembrolizumab should be considered for chemotherapy refractory disease. The role of next generation sequencing is experimental and targeted therapies are not routinely recommended outside of a clinical trial.

\subsection{Summary of Evidence}

The standard first line therapy options for patients with metastatic pancreatic ductal adenocarcinoma (mPDAC) with good performance status include FOLFIRINOX and gemcitabine and nab-paclitaxel [42,43]. The choice between the two regimens is often dependent on the patient's co-morbidities and physician/patient preference. Although survival outcomes are inferior with gemcitabine alone, it has demonstrated symptomatic clinical benefit, and can be considered when combination therapy is not feasible [58].

For patients who have progressed from FOLFIRINOX, there is no standard chemotherapy proven with phase III evidence. However, inferring from retrospective studies (ranging from 7 to 69 patients), gemcitabine with nab-paclitaxel has an overall response rate (ORR) of approximately $18 \%$ with a median PFS of 3 months and median OS of 5-8 months from the date of starting second line therapy [59-66]. Given the regimen appears efficacious in the second line, it is the preferred regimen for patients who can tolerate combination chemotherapy. For those that cannot, gemcitabine monotherapy may be considered [59].

For patients who have progressed on gemcitabine and nab-paclitaxel, liposomal irinotecan and fluorouracil as per NAPOLI-1 trial and OFF regimen as per CONKO-3 trial are reasonable treatment options with phase III evidence [67,68]. Of note, the PANCREOX study showed conflicting results with the mFOLFOX6 regimen having inferior mOS compared to infusional 5FU (6.1 vs. 9.9 months, HR 1.78 (95\%CI 1.08-2.93), $p=0.024$ ) [69]. Therefore, if an oxaliplatin based regimen is utilized then oxaliplatin should be given as per the OFF regimen.

For patients with mPDAC who have known germline BRCA mutations or DNA damage repair (DDR) genes then second line treatment with platinum-based chemotherapy may be considered, especially if they are platinum naïve. This is supported by the Know Your Tumour Type study, where patients with advanced PDAC with DDR $(\mathrm{n}=54)$ was predictive of significant improvement in mOS if treated with platinum-based therapy (2.37 
vs. 1.45 years, $p<0.0001$ ) [70]. Similarly, in a smaller study of 71 patients with somatic BRCA mutations where those treated with platinum $(n=22)$ versus not $(n=21)$, mOS was improved to 22 vs. 9 months, $p=0.03915$ [71]. The DDR genes of interest are pathogenic alterations in BRCA1/2, PALB2, ATM, ATR, ATRX, BAP1, BARD1, BRIP1, CHEK1/2, $\mathrm{RAD} 50 / 51 / 51 \mathrm{~B}$, or $\mathrm{FANCA} / \mathrm{C} / \mathrm{D} 2 / \mathrm{E} / \mathrm{F} / \mathrm{G} / \mathrm{L}$ if this prospective trial evidence is to be applied. Of note, patients with DDR aberrations may also be more sensitive to 5-FU and irinotecan [72]. For liposomal irinotecan, the benefit seems to be in irinotecan naïve patients where a retrospective study by Glassman DC et al. showed reduced ORR and mOS in prior irinotecan treated patients and naïve patients had similar benefit as per the NAPOLI-1 trial [73].

Beyond chemotherapy, emerging actionable targets with survival benefits are being identified through next generation sequencing (NGS), particularly in patients with KRAS wildtype mPDAC [74]. However, targeted therapies are not routinely considered outside of a clinical trial. In $0.5-0.8 \%$ mPDAC patients with deficiency in mismatch repair protein (dMMR) or microsatellite instability (MSI-H), pembrolizumab has shown to be efficacious [75-77]. NTRK fusion inhibitors with larorectinib and entrectinib have been recognized as efficacious across multiple tumor types including MPDAC for patients who harbor the fusion $[78,79]$. NRG1 is another recurrent fusion found across multiple tumor types with a prevalence of approximately $0.3 \%$ in mPDAC [80]. There is emerging evidence that it can be targeted with afatinib with a quick and durable response [81,82]. The logistical challenge in reliable detection of such a rare mutation across the population poses a barrier to its utility in today's clinical practice.

There is recognition of $5-10 \%$ hereditary cancer risk associated with mPDAC diagnosis, which may be higher in certain subpopulations [83-85]. ASCO and NCCN guidelines recommend that germline testing be considered for all patients with $\mathrm{mPDAC}$ in recognition that up to half of the patients may not have a classical family history and germline BRCA mutations may carry treatment implications [86-89]. However, the implementation of testing across the population remains a significant barrier and is subject to ongoing research [89]. After an initial response to platinum-based chemotherapy, the use of maintenance olaparib compared to placebo demonstrated improved PFS, suggesting activity with the parp inhibitor, but the lack of OS improvement and use of placebo as a control (as opposed to ongoing chemotherapy) casts doubt over its utility despite FDA approval [85].

\section{Question 7}

What is the preferred adjuvant therapy for patients with early stage biliary tract cancer? What are the preferred first- and second-line systemic therapies in patients with advanced biliary tract cancer? What are potential targeted treatments for biliary tract cancer?

\subsection{Recommendations}

- In the adjuvant setting, capecitabine for 6 months is the preferred option. For positive margin disease, patients should be reviewed in a multi-disciplinary fashion to determine if radiotherapy is reasonable.

- In patients with advanced biliary tract cancers, the preferred first line option is gemcitabine and cisplatin. Gemcitabine is an option in patients who cannot tolerate combination therapy.

- $\quad$ Fluoropyrimidine-based chemotherapy may be considered in the second line setting.

- The role of molecular testing and targeted therapy is evolving. For MSI-high, MMRdeficient advanced biliary cancer, pembrolizumab should be considered for chemotherapy refractory disease.

\subsection{Summary of Evidence}

The phase III BILCAP trial, randomized 447 patients with resected biliary tract cancers to receive eight cycles of capecitabine (1250 mg/m² twice daily on days 1-14 every 21 days) 
or placebo [90]. In total, $38 \%$ had R1 resection. The primary intention-to-treat analysis for OS did not meet statistical significance (51.1 vs. 36.4 months, HR $0.8195 \%$ CI $0.63-$ $1.04, p=0.097$ ), while per-protocol analysis did (53 vs. 36 months, HR 0.75, 95\% CI $0.58-0.97, p=0.028$ ). Additionally, pre-planned sensitivity analyses adjusting for nodal status, disease grade and sex suggested that capecitabine was beneficial (HR 0.71, 95\% CI $0.55-0.92, p=0.010$ ) and RFS was improved in both intention to treat and per-protocol analysis. Given the magnitude of benefit and supportive analyses, adjuvant capecitabine has been adopted as a new standard of care for patients with resected biliary tract cancer. The benefit of adjuvant radiation or chemoradiation is unclear as there is no prospective, randomized data to support its routine use. However, retrospective data suggests potential benefit, particularly in patients with positive margins, so it is reasonable to have these cases reviewed in a multidisciplinary fashion to determine if radiotherapy should be considered [91].

Cisplatin and gemcitabine are recommended for first line treatment of metastatic cholangiocarcinoma based on the multicenter ABC-02 trial. In this study, 410 patients were randomly assigned to eight cycles of cisplatin $\left(25 \mathrm{mg} / \mathrm{m}^{2}\right)$ followed by gemcitabine $\left(1000 \mathrm{mg} / \mathrm{m}^{2}\right)$ on days 1 and 8 every 21 days, or gemcitabine alone $\left(1000 \mathrm{mg} / \mathrm{m}^{2}\right.$ on days 1,8 , and 15 every 28 days) [92]. Median OS was significantly greater with combination therapy (11.7 versus 8.1 months), as was median PFS ( 8 versus 5 months). For second-line, ABC-06 was the first prospective phase III trial evaluating the benefit of chemotherapy after Cisplatin and Gemcitabine in patients with advanced cholangiocarcinoma. The trial compared infusional fluorouracil plus leucovorin and oxaliplatin (FOLFOX) with active symptom control. FOLFOX improved OS at 6 (61 versus 36\%) and 12 months (26 versus $11 \%$ ) [93]. The incremental benefit of oxaliplatin in addition to fluoropyrimidine alone after cisplatin and gemcitabine is unclear. Whilst there is a lack of prospective evidence, retrospective comparisons indicate oxaliplatin combination achieves a higher objective response rate ( 8 vs. $1 \%, p=0.009)$, but PFS and OS are not clearly different from a fluoropyrimidine alone [94].

Molecular targeted therapy has been an emerging area of interest for biliary tract cancers. As with other cancers that are $\mathrm{dMMR} / \mathrm{MSI}-\mathrm{H}$, immunotherapy has demonstrated activity for this disease subtype [74,95]. Similarly, TRK inhibitors like larorectinib and entrectinib have been recognized as efficacious for TRK-fusion positive cholangiocarcinomas as well $[77,78]$. Several trials are also evaluating the role of FGFR2 transloactions, which are present in approximately $13 \%$ of patients with cholangiocarcinoma [96]. Pemigatinib has subsequently received FDA approval due to an objective response rate of $36 \%$ and disease control rate of $80 \%$ [97]. Infigratinib is another FGFR2 targeted therapy that has received accelerated approval by the FDA [98]. The emerging number of targeted therapies available for intrahepatic cholangiocarcinomas has led to a blanket recommendation by ESMO for routine next generation sequencing for these cancers [99]. However, funding for such testing remains elusive in the publicly funded context of Canada.

Funding: The 2019 WCGCCC received unrestricted educational grants from Hoffmann-La Roche, Amgen Canada, IPSEN Biopharmaceutical Canada, Taiho Pharma Canada, BTG International Canada, Eli Lilly Canada Inc., Merck, AstraZeneca, Eisai Inc., Celgene, Servier Canada Inc., and Bayer Canada Inc. During the entire process, the sponsors had no influence whatsoever over the development of the guidelines, and they did not review or read the guidelines before submission. No author was compensated for their work on this article.

Institutional Review Board Statement: Not applicable.

Informed Consent Statement: Not applicable.

Data Availability Statement: Not applicable.

Acknowledgments: The WCGCCC organizing committee thanks all meeting participants for their contributions to the development of this consensus statement. In addition, the committee thanks the meeting sponsors and Buksa Strategic Conference Services for support in organizing the meeting. 
Conflicts of Interest: Author R.L.-Y. has had advisory roles for Eisai, Ipsen, AstraZeneca, Roche and Celgene. Author J.D. has clinical trials for BMS, Merck, MedImmune, Astellas Array BioPharma, and is a consultant for AstraZeneca, Eisai, Taiho, and Amgen. Author L.D. is in a licensing agreement with Raysearch. Author C.A.K. received an unrelated research grant from Celgene Inc. Author H.L. received honoraria from Merck, BMS, AstraZeneca, Eisai, Taiho, Roche, Amgen, and Bayer for consultant work. Author K.M. has an advisory role for Pfizer Canada, Eisai Inc., Bayer Canada and has received clinical trials funding from Deciphera Pharmaceuticals, BluePrint Medicines, AstraZeneca. Author V.T. is on the Advisory Board for AstraZeneca, Eisai, Ipsen, and Roche and has also received Clinical Trials/Research Funding through his institution from AstraZeneca, Eisai, Exelixis, Ipsen, Merck, Roche. Author A.Z. has provided consult work for Eisai Inc. The remaining authors declare no conflicts of interest. The funders had no role in the design of the study; in the collection, analyses, or interpretation of data; in the writing of the manuscript, or in the decision to publish the results.

\section{References}

1. Kim, N.; Kim, H.J.; Won, J.Y.; Kim, D.Y.; Han, K.-H.; Jung, I.; Seong, J. Retrospective analysis of stereotactic body radiation therapy efficacy over radiofrequency ablation for hepatocellular carcinoma. Radiother. Oncol. 2019, 131, 81-87. [CrossRef]

2. Yoon, S.M.; Ryoo, B.Y.; Lee, S.J.; Kim, J.H.; Shin, J.H.; An, J.H.; Lee, H.C.; Lim, Y.S. Efficacy and safety of transarterial chemoembolization plus external beam radiotherapy vs. sorafenib in hepatocellular carcinoma with macroscopic vascular invasion: A randomized clinical trial. JAMA Oncol. 2018, 4, 661-669. [CrossRef] [PubMed]

3. Llovet, J.M.; Ricci, S.; Mazzaferro, V.; Hilgard, P.; Gane, E.; Blanc, J.F.; De Oliveira, A.C.; Santoro, A.; Raoul, J.L.; Forner, A.; et al. Sorafenib in Advanced Hepatocellular Carcinoma. N. Engl. J. Med. 2008, 359, 378-390. [CrossRef]

4. Cheng, A.-L.; Kang, Y.-K.; Chen, Z.; Tsao, C.-J.; Qin, S.; Kim, J.S.; Luo, R.; Feng, J.; Ye, S.; Yang, T.-S.; et al. Efficacy and safety of sorafenib in patients in the Asia-Pacific region with advanced hepatocellular carcinoma: A phase III randomised, double-blind, placebo-controlled trial. Lancet Oncol. 2009, 10, 25-34. [CrossRef]

5. Kudo, M.; Finn, R.S.; Qin, S.; Han, K.-H.; Ikeda, K.; Piscaglia, F.; Baron, A.; Park, J.-W.; Han, G.; Jassem, J.; et al. Lenvatinib versus sorafenib in first-line treatment of patients with unresectable hepatocellular carcinoma: A randomised phase 3 non-inferiority trial. Lancet 2018, 391, 1163-1173. [CrossRef]

6. Lencioni, R.; Kudo, M.; Ye, S.; Bronowicki, J.; Chen, X.; Dagher, L.; Furuse, J.; Geschwind, J.F.; De Guevara, L.L.; Papandreou, C.; et al. GIDEON (Global Investigation of therapeutic DE cisions in hepatocellular carcinoma and Of its treatment with sorafeNib): Second interim analysis. Int. J. Clin. Pract. 2014, 68, 609-617. [CrossRef]

7. Bruix, J.; Qin, S.; Merle, P.; Granito, A.; Huang, Y.-H.; Bodoky, G.; Pracht, M.; Yokosuka, O.; Rosmorduc, O.; Breder, V.; et al. Regorafenib for patients with hepatocellular carcinoma who progressed on sorafenib treatment (RESORCE): A randomised, double-blind, placebo-controlled, phase 3 trial. Lancet 2017, 389, 56-66. [CrossRef]

8. Translator Abou-Alfa, G.K.; Meyer, T.; Cheng, A.-L.; El-Khoueiry, A.B.; Rimassa, L.; Ryoo, B.-Y.; Cicin, I.; Merle, P.; Chen, Y.; Park, J.-W.; et al. Cabozantinib in Patients with Advanced and Progressing Hepatocellular Carcinoma. N. Engl. J. Med. 2018, 379, 54-63. [CrossRef]

9. Zhu, A.X.; Kang, Y.-K.; Yen, C.-J.; Finn, R.S.; Galle, P.R.; Llovet, J.M.; Assenat, E.; Brandi, G.; Pracht, M.; Lim, H.Y.; et al. Ramucirumab after sorafenib in patients with advanced hepatocellular carcinoma and increased $\alpha$-fetoprotein concentrations (REACH-2): A randomised, double-blind, placebo-controlled, phase 3 trial. Lancet Oncol. 2019, 20, 282-296. [CrossRef]

10. Finn, R.S.; Ryoo, B.-Y.; Merle, P.; Kudo, M.; Bouattour, M.; Lim, H.-Y.; Breder, V.V.; Edeline, J.; Chao, Y.; Ogasawara, S.; et al. Results of KEYNOTE-240: Phase 3 study of pembrolizumab (Pembro) vs. best supportive care (BSC) for second line therapy in advanced hepatocellular carcinoma (HCC). J. Clin. Oncol. 2019, 37, 4004. [CrossRef]

11. Yau, T.; Park, J.W.; Finn, R.S.; Cheng, A.; Mathurin, P.; Edeline, J.; Kudo, M.; Han, K.; Harding, J.J.; Merle, P.; et al. CheckMate 459: A Randomised, Multi-Center Phase 3 Study of Nivolumab (NIVO) vs. Sorafenib (SOR) as First-Line (1L) Treatment in Patients (pts) with Advanced Hepatocellular Carcinoma. Ann. Oncol. 2019, 30, v874-v875. [CrossRef]

12. Cheng, A.-L.; Qin, S.; Ikeda, M.; Galle, P.; Ducreux, M.; Zhu, A.; Kim, T.-Y.; Kudo, M.; Breder, V.; Merle, P.; et al. IMbrave150: Efficacy and safety results from a ph III study evaluating atezolizumab (atezo) + bevacizumab (bev) vs. sorafenib (Sor) as first treatment (tx) for patients (pts) with unresectable hepatocellular carcinoma (HCC). Ann. Oncol. 2019, 30, ix186-ix187. [CrossRef]

13. Canadian Agency for Drugs and Technologies in Health (CADTH). Atezolizumab-Bevacizumab HCC—pERC Final Recommendation; CADTH: Toronto, ON, Canada, 2020. Available online: https://cadth.ca/sites/default/files/pcodr/Reviews2020/1021 7AtezolizumabBevacizumabHCC_fnRec_EC_Post17Nov2020_final.pdf (accessed on 3 August 2021).

14. Yoo, C.; Kim, J.H.; Ryu, M.-H.; Park, S.R.; Lee, J.J.X.; Tai, W.M.D.; Chan, S.L.; Ryoo, B.-Y. Clinical outcomes with multikinase inhibitors after progression on first-line atezolizumab plus bevacizumab in patients with advanced hepatocellular carcinoma: A multinational, multicenter retrospective study. J. Clin. Oncol. 2021, 39, 272. [CrossRef]

15. Canadian Agency for Drugs and Technologies in Health (CADTH). Unresectable Hepatocellular Carcinoma-Provisional Funding Algorithm; CADTH: Toronto, ON, Canada, 2021. Available online: https://www.cadth.ca/sites/default/files/pdf/ph0003-000_ hcc-report-final.pdf (accessed on 3 August 2021).

16. Gärtner, S.; Krüger, J.; Aghdassi, A.A.; Steveling, A.; Simon, P.; Lerch, M.M.; Mayerle, J. Nutrition in Pancreatic Cancer: A Review. Gastrointest. Tumors 2016, 2, 195-202. [CrossRef] 
17. Gilliland, T.M.; Villafane-Ferriol, N.; Shah, K.P.; Shah, R.M.; Tran Cao, H.S.; Massarweh, N.N.; Silberfein, E.J.; Choi, E.A.; Hsu, C.; McElhany, A.L.; et al. Nutritional and Metabolic Derangements in Pancreatic Cancer and Pancreatic Resection. Nutrients 2017, 9 , 243. [CrossRef] [PubMed]

18. Arends, J.; Baracos, V.; Bertz, H.; Bozzetti, F.; Calder, P.C.; Deutz, N.E.P.; Erickson, N.; Laviano, A.; Lisanti, M.P.; Lobo, D.N.; et al. ESPEN expert group recommendations for action against cancer-related malnutrition. Clin. Nutr. 2017, 36, 1187-1196. [CrossRef] [PubMed]

19. Capurso, G.; Traini, M.; Piciucchi, M.; Signoretti, M.; Arcidiacono, P.G. Exocrine pancreatic insufficiency: Prevalence, diagnosis, and management. Clin. Exp. Gastroenterol. 2019, 12, 129-139. [CrossRef] [PubMed]

20. Bartel, M.; Asbun, H.; Stauffer, J.; Raimondo, M. Pancreatic exocrine insufficiency in pancreatic cancer: A review of the literature. Dig. Liver Dis. 2015, 47, 1013-1020. [CrossRef] [PubMed]

21. SEER Cancer Statistics Factsheets: Pancreas Cancer; National Cancer Institute: Bethesda, MD, USA. Available online: http: // seer.cancer.gov/statfacts/html/pancreas.html (accessed on 29 December 2020).

22. Neoptolemos, J.; Stocken, D.D.; Friess, H.; Bassi, C.; Dunn, J.; Hickey, H.; Beger, H.; Fernandez-Cruz, L.; Dervenis, C.; Lacaine, F.; et al. A Randomized Trial of Chemoradiotherapy and Chemotherapy after Resection of Pancreatic Cancer. N. Engl. J. Med. 2004, 350, 1200-1210. [CrossRef]

23. Neoptolemos, J.P.; The European Study Group of Pancreatic Cancer; Stocken, D.D.; Smith, C.T.; Bassi, C.; Ghaneh, P.; Owen, E.; Moore, M.; Padbury, R.; Doi, R.; et al. Adjuvant 5-fluorouracil and folinic acid vs. observation for pancreatic cancer: Composite data from the ESPAC-1 and -3(v1) trials. Br. J. Cancer 2009, 100, 246-250. [CrossRef]

24. Oettle, H.; Post, S.; Neuhaus, P.; Gellert, K.; Langrehr, J.; Ridwelski, K.; Schramm, H.; Fahlke, J.; Zuelke, C.; Burkart, C.; et al. Adjuvant chemotherapy with gemcitabine vs. observation in patients undergoing curative-intent resection of pancreatic cancer: A randomized controlled trial. JAMA 2007, 297, 267-277. [CrossRef]

25. Oettle, H.; Neuhaus, P.; Hochhaus, A.; Hartmann, J.Y.; Gellert, K.; Ridwelski, K.; Niedergethmann, M.; Zülke, C.; Fahlke, J.; Arning, M.B.; et al. Adjuvant chemotherapy with gemcitabine and long-term outcomes among patients with resected pancreatic cancer: The CONKO-001 randomized trial. JAMA 2013, 310, 1473-1481. [CrossRef] [PubMed]

26. Neoptolemos, J.P.; Stocken, D.D.; Bassi, C.; Ghaneh, P.; Cunningham, D.; Goldstein, D.; Padbury, R.; Moore, M.J.; Gallinger, S.; Mariette, C.; et al. Adjuvant chemotherapy with fluorouracil plus folinic acid vs. gemcitabine following pancreatic cancer resection: A randomized controlled trial. JAMA 2010, 304, 1073-1081. [CrossRef]

27. Neoptolemos, J.P.; Palmer, D.H.; Ghaneh, P.; Psarelli, E.E.; Valle, J.W.; Halloran, C.M.; Faluyi, O.; O'Reilly, D.A.; Cunningham, D.; Wadsley, J.; et al. Comparison of adjuvant gemcitabine and capecitabine with gemcitabine monotherapy in patients with resected pancreatic cancer (ESPAC-4): A multicentre, open-label, randomised, phase 3 trial. Lancet 2017, 389, 1011-1024. [CrossRef]

28. Tempero, M.A.; Reni, M.; Riess, H.; Pelzer, U.; O’Reilly, E.M.; Winter, J.M.; Oh, D.-Y.; Li, C.-P.; Tortora, G.; Chang, H.-M.; et al. APACT: Phase III, multicenter, international, open-label, randomized trial of adjuvant nab-paclitaxel plus gemcitabine (nab-P/G) vs. gemcitabine (G) for surgically resected pancreatic adenocarcinoma. J. Clin. Oncol. 2019, 37, 4000. [CrossRef]

29. Conroy, T.; Hammel, P.; Hebbar, M.; Ben Abdelghani, M.; Wei, A.C.; Raoul, J.-L.; Choné, L.; Francois, E.; Artru, P.; Biagi, J.J.; et al. FOLFIRINOX or Gemcitabine as Adjuvant Therapy for Pancreatic Cancer. N. Engl. J. Med. 2018, 379, 2395-2406. [CrossRef]

30. Palta, M.; Godfrey, D.; Goodman, K.A.; Hoffe, S.; Dawson, L.A.; Dessert, D.; Hall, W.A.; Herman, J.M.; Khorana, A.A.; Merchant, N.; et al. Radiation Therapy for Pancreatic Cancer: Executive Summary of an ASTRO Clinical Practice Guideline. Pract. Radiat. Oncol. 2019, 9, 322-332. [CrossRef]

31. Tempero, M.A.; Malafa, M.P.; Behrman, S.W.; Benson, A.B.; Casper, E.S.; Chiorean, E.G.; Chung, V.; Cohen, S.J.; Czito, B.; Engebretson, A.; et al. Pancreatic adenocarcinoma, version 2.2014: Featured updates to the NCCN guidelines. J. Natl. ComPract. Cancer Netw. 2014, 12, 1083-1093. [CrossRef] [PubMed]

32. Seufferlein, T.; Bachet, J.B.; Van Cutsem, E.; Rougier, P.; ESMO Guidelines Working Group. Pancreatic adenocarcinoma: ESMOESDO Clinical Practice Guidelines for diagnosis, treatment and follow-up. Ann. Oncol. 2012, 23 (Suppl. 7), vii33-vii40. [CrossRef]

33. He, J.; Page, A.J.; Weiss, M.; Wolfgang, C.L.; Herman, J.M.; Pawlik, T.M. Management of borderline and locally advanced pancreatic cancer: Where do we stand? World J. Gastroenterol. 2014, 20, 2255-2266. [CrossRef] [PubMed]

34. Callery, M.P.; Chang, K.J.; Fishman, E.K.; Talamonti, M.S.; Traverso, L.W.; Linehan, D.C. Pretreatment Assessment of Resectable and Borderline Resectable Pancreatic Cancer: Expert Consensus Statement. Ann. Surg. Oncol. 2009, 16, 1727-1733. [CrossRef] [PubMed]

35. Varadhachary, G.R.; Tamm, E.P.; Abbruzzese, J.L.; Xiong, H.Q.; Crane, C.H.; Wang, H.; Lee, J.E.; Pisters, P.W.T.; Evans, D.B.; Wolff, R.A. Borderline Resectable Pancreatic Cancer: Definitions, Management, and Role of Preoperative Therapy. Ann. Surg. Oncol. 2006, 13, 1035-1046. [CrossRef]

36. Al-Hawary, M.M.; Francis, I.R.; Chari, S.T.; Fishman, E.; Hough, D.M.; Lu, D.S.; Macari, M.; Megibow, A.; Miller, F.H.; Mortele, K.J.; et al. Pancreatic Ductal Adenocarcinoma Radiology Reporting Template: Consensus Statement of the Society of Abdominal Radiology and the American Pancreatic Association. Radiology 2014, 270, 248-260. [CrossRef] [PubMed]

37. Lee, Y.S.; Lee, J.-C.; Yang, S.Y.; Kim, J.; Hwang, J.-H. Neoadjuvant therapy versus upfront surgery in resectable pancreatic cancer according to intention-to-treat and per-protocol analysis: A systematic review and meta-analysis. Sci. Rep. 2019, 9, 1-8. [CrossRef] [PubMed] 
38. Sohal, D.; Lew, D.; Ahmad, S.; Gandhi, N.; Shaalan Beg, M.; Wang-Gillam, A.; Wade, J.L.; Guthrie, K.A.; Lowy, A.M.; Philip, A.A.; et al. S WOG S1505: Initial findings on eligibility and neoadjuvant chemotherapy experience with mFOLFIRINOX versus gemcitabine/nab-paclitaxel for resectable pancreatic adenocarcinoma. J. Clin. Oncol. 2019, 37, 4137. [CrossRef]

39. Murphy, J.E.; Wo, J.Y.; Ryan, D.P.; Jiang, W.; Yeap, B.Y.; Drapek, L.C.; Blaszkowsky, L.S.; Kwak, E.L.; Allen, J.N.; Clark, J.W.; et al. Total Neoadjuvant Therapy with FOLFIRINOX Followed by Individualised Chemoradiotherapy for Borderline Resectable Pancreatic Adenocarcinoma: A Phase 2 Clinical Trial. JAMA Oncol. 2018, 4, 963. [CrossRef] [PubMed]

40. Versteijne, E.; Vogel, J.A.; Besselink, M.G.; Busch, O.R.C.; Wilmink, J.W.; Daams, J.; van Eijck, C.H.J.; Koerkamp, B.G.; Rasch, C.R.N.; van Tienhoven, G. Meta-analysis comparing upfront surgery with neoadjuvant treatment in patients with resectable or borderline resectable pancreatic cancer. J. Br. Surg. 2018, 105, 946-958. [CrossRef]

41. Ferrone, C.R.; Marchegiani, G.; Hong, T.S.; Ryan, D.P.; Deshpande, V.; McDonnell, E.I.; Sabbatino, F.; Santos, D.D.; Allen, J.N.; Blaszkowsky, L.S.; et al. Radiological and Surgical Implications of Neoadjuvant Treatment with FOLFIRINOX for Locally Advanced and Borderline Resectable Pancreatic Cancer. Ann. Surg. 2015, 261, 12-17. [CrossRef]

42. Conroy, T.; Desseigne, F.; Ychou, M.; Bouché, O.; Guimbaud, R.; Bécouarn, Y.; Adenis, A.; Raoul, J.-L.; Gourgou-Bourgade, S.; De La Fouchardière, C.; et al. FOLFIRINOX versus Gemcitabine for Metastatic Pancreatic Cancer. N. Engl. J. Med. 2011, 364, 1817-1825. [CrossRef]

43. Von Hoff, D.D.; Ervin, T.; Arena, F.P.; Chiorean, E.G.; Infante, J.; Moore, M.; Seay, T.; Tjulandin, S.A.; Ma, W.W.; Saleh, M.N.; et al. Increased Survival in Pancreatic Cancer with nab-Paclitaxel plus Gemcitabine. N. Engl. J. Med. 2013, 369, 1691-1703. [CrossRef]

44. Mukherjee, S.; Hurt, C.; Bridgewater, J.; Falk, S.; Cummins, S.; Wasan, H.; Crosby, T.; Jephcott, C.; Roy, R.; Radhakrishna, G.; et al. Gemcitabine-based or capecitabine-based chemoradiotherapy for locally advanced pancreatic cancer (SCALOP): A multicentre, randomised, phase 2 trial. Lancet Oncol. 2013, 14, 317-326. [CrossRef]

45. Versteijne, E.; Suker, M.; Groothuis, K.; Akkermans-Vogelaar, J.M.; Besselink, M.G.; Bonsing, B.A.; Buijsen, J.; Busch, O.R.; Creemers, G.J.M.; van Dam, R.M.; et al. Preoperative Chemoradiotherapy versus immediate surgery for Resectable and borderline Resectable pancreatic Cancer: Results of the Dutch randomized phase III PREOPANC trial. J. Clin. Oncol. 2020, 38, 1763-1773. [CrossRef]

46. Van Eijck, C.H.; Versteijne, E.; Suker, M.; Groothuis, K.; Besselink, M.G.; Busch, O.R.; Bonsing, B.A.; Koerkamp, B.G.; de Hingh, I.H.; Festen, S.; et al. Preoperative chemoradiotherapy to improve overall survival in pancreatic cancer: Long-term results of the multicenter randomized phase III PREOPANC trial. J. Clin. Oncol. 2021, 39, 4016. [CrossRef]

47. Sohal, D.P.S.; Duong, M.; Ahmad, S.A.; Gandhi, N.S.; Beg, M.S.; Wang-Gillam, A.; Wade, J.L., 3rd; Chiorean, E.G.; Guthrie, K.A.; Lowy, A.M.; et al. Efficacy of Perioperative Chemotherapy for Resectable Pancreatic Adenocarcinoma: A Phase 2 Randomized Clinical Trial. JAMA Oncol. 2021, 7, 421. [CrossRef]

48. Janssen, Q.P.; The Dutch Pancreatic Cancer Group; van Dam, J.L.; Bonsing, B.A.; Bos, H.; Bosscha, K.P.; Coene, P.P.L.O.; van Eijck, C.H.J.; de Hingh, I.H.J.T.; Karsten, T.M.; et al. Total neoadjuvant FOLFIRINOX versus neoadjuvant gemcitabine-based chemoradiotherapy and adjuvant gemcitabine for resectable and borderline resectable pancreatic cancer (PREOPANC-2 trial): Study protocol for a nationwide multicenter randomized controlled trial. BMC Cancer 2021, 21, 1-8. [CrossRef]

49. Lee, S.M.; Lee, J.M.; Ahn, S.J.; Kang, H.-J.; Yang, H.K.; Yoon, J.H. LI-RADS Version 2017 versus Version 2018: Diagnosis of Hepatocellular Carcinoma on Gadoxetate Disodium-enhanced MRI. Radiology 2019, 292, 655-663. [CrossRef] [PubMed]

50. Cholongitas, E.; Papatheodoridis, G.V.; Vangeli, M.; Terreni, N.; Patch, D.; Burroughs, A.K. Systematic review: The model for end-stage liver disease-should it replace Child-Pugh's classification for assessing prognosis in cirrhosis? Aliment. Pharmacol. Ther. 2005, 22, 1079-1089. [CrossRef] [PubMed]

51. Venkatesh, S.K.; Yin, M.; Ehman, R.L. Magnetic resonance elastography of liver: Technique, analysis, and clinical applications. J. Magn. Reson. Imaging 2013, 37, 544-555. [CrossRef]

52. Lee, S.; Kang, T.W.; Cha, D.I.; Song, K.D.; Lee, M.W.; Rhim, H.; Lim, H.K.; Sinn, D.H.; Kim, J.M.; Kim, K. Radiofrequency ablation vs. surgery for perivascular hepatocellular carcinoma: Propensity score analyses of long-term outcomes. J. Hepatol. 2018, 69, 70-78. [CrossRef]

53. Mazzaferro, V.M.; Regalia, E.; Doci, R.; Andreola, S.; Pulvirenti, A.; Bozzetti, F.; Montalto, F.; Ammatuna, M.; Morabito, A.; Gennari, L. Liver Transplantation for the Treatment of Small Hepatocellular Carcinomas in Patients with Cirrhosis. N. Engl. J. Med. 1996, 334, 693-700. [CrossRef] [PubMed]

54. Sapisochin, G.; Goldaracena, N.; Laurence, J.M.; Dib, M.; Barbas, A.; Ghanekar, A.; Cleary, S.; Lilly, L.; Cattral, M.S.; Marquez, M.; et al. The extended Toronto criteria for liver transplantation in patients with hepatocellular carcinoma: A prospective validation study. Hepatology 2016, 64, 2077-2088. [CrossRef]

55. Degroote, H.; Callebout, E.; Iesari, S.; Dekervel, J.; Schreiber, J.; Pirenne, J.; Verslype, C.; Ysebaert, D.; Michielsen, P.; Lucidi, V.; et al. Extended criteria for liver transplantation in hepatocellular carcinoma. A retrospective, multicentric validation study in Belgium. Surg. Oncol. 2020, 33, 231-238. [CrossRef] [PubMed]

56. Llovet, J.M.; Di Bisceglie, A.M.; Bruix, J.; Kramer, B.S.; Lencioni, R.; Zhu, A.X.; Sherman, M.; Schwartz, M.; Lotze, M.; Talwalkar, J.; et al. Design and Endpoints of Clinical Trials in Hepatocellular Carcinoma. J. Natl. Cancer Inst. 2008, 100, 698-711. [CrossRef]

57. Burris, H.A., 3rd; Moore, M.J.; Andersen, J.; Green, M.R.; Rothenberg, M.L.; Modiano, M.R.; Cripps, M.C.; Portenoy, R.K.; Storniolo, A.M.; Tarassoff, P.; et al. Improvements in survival and clinical benefit with gemcitabine as first-line therapy for patients with advanced pancreas cancer: A randomized trial. J. Clin. Oncol. 1997, 15, 2403-2413. [CrossRef] [PubMed] 
58. Chan, E.; Hong, T.S.; Clark, J.W.; Blaszkowsky, L.S.; Allen, J.N.; Zhu, A.; Goyal, L.; Murphy, J.E.; Kwak, E.L.; Wo, J.Y.; et al. Gemcitabine $(\mathrm{G})$ + nab-paclitaxel (nab-P) versus $\mathrm{G}$ in patients (pts) with advanced pancreatic cancer (PDAC) after FOLFIRINOX: A single center, retrospective review. J. Clin. Oncol. 2016, 34, 348. [CrossRef]

59. Zhang, Y.; Hochster, H.; Stein, S.; Lacy, J. Gemcitabine plus nab-paclitaxel for advanced pancreatic cancer after first-line FOLFIRINOX: Single institution retrospective review of efficacy and toxicity. Exp. Hematol. Oncol. 2015, 4, 1-5. [CrossRef] [PubMed]

60. Zaniboni, A.; Bertocchi, P.; Abeni, C.; Ogliosi, C.; Rizzi, A.; Rota, L.; Di Biasi, B.; Prochilo, T.; Aroldi, F.; Meriggi, F. Gemcitabine plus nab-paclitaxel as second line and beyond for metastatic pancreatic cancer (MPC): A single institution retrospective analysis. J. Clin. Oncol. 2014, 32, e15202. [CrossRef]

61. Nguyen, K.T.; Kalyan, A.; Beasley, H.S.; Singhi, A.D.; Sun, W.; Zeh, H.J.; Normolle, D.; Bahary, N. Gemcitabine/nab-paclitaxel as second-line therapy following FOLFIRINOX in metastatic/advanced pancreatic cancer-Retrospective analysis of response. J. Gastrointest. Oncol. 2017, 8, 556-565. [CrossRef]

62. Portal, A.; Pernot, S.; Tougeron, D.; Arbaud, C.; Bidault, A.T.; De La Fouchardière, C.; Hammel, P.; Lecomte, T.; Dréanic, J.; Coriat, R.; et al. Nab-paclitaxel plus gemcitabine for metastatic pancreatic adenocarcinoma after Folfirinox failure: An AGEO prospective multicentre cohort. Br. J. Cancer 2015, 113, 989-995. [CrossRef]

63. Zhang, H.; Kellett, C.; Lambert, P.; Kim, C.A. Efficacy and Tolerability of Second-line Nab-paclitaxel and Gemcitabine After Failure of First-line FOLFIRINOX for Advanced Pancreas Cancer: A Single-institution Experience. Clin. Color. Cancer 2018, 17, e451-e456. [CrossRef] [PubMed]

64. Schmidt, S.L.; Durkal, V.; Jayavalsan, S.P.; Thomas, J.P.; Ritch, P.S.; Erickson, B.; Christians, K.K.; Tsai, S.; Evans, D.B.; George, B. Outcomes in metastatic pancreatic adenocarcinoma (MPAC) patients treated with FOLFIRINOX (FFX)/FOLFOX(FX) and gemcitabine + nab-paclitaxel (NabG). J. Clin. Oncol. 2016, 34, 397. [CrossRef]

65. de Jesus, V.H.F.; Camandaroba, M.P.G.; Donadio, M.D.S.; Cabral, A.; Muniz, T.P.; de Moura Leite, L.; Sant'Ana, L.F. Retrospective analysis of efficacy and safety of gemcitabine based chemotherapy in patients with metastatic pancreatic adenocarcinoma experiencing disease progression on FOLFIRINOX. J. Gastrointest. Oncol. 2018, 9, 806-819. [CrossRef]

66. Oettle, H.; Riess, H.; Stieler, J.M.; Heil, G.; Schwaner, I.; Seraphin, J.; Görner, M.; Mölle, M.; Greten, T.F.; Lakner, V.; et al. Second-Line Oxaliplatin, Folinic Acid, and Fluorouracil Versus Folinic Acid and Fluorouracil Alone for Gemcitabine-Refractory Pancreatic Cancer: Outcomes From the CONKO-003 Trial. J. Clin. Oncol. 2014, 32, 2423-2429. [CrossRef] [PubMed]

67. Wang-Gillam, A.; Li, C.-P.; Bodoky, G.; Dean, A.; Shan, Y.-S.; Jameson, G.; Macarulla, T.; Lee, K.-H.; Cunningham, D.; Blanc, J.F.; et al. Nanoliposomal irinotecan with fluorouracil and folinic acid in metastatic pancreatic cancer after previous gemcitabine-based therapy (NAPOLI-1): A global, randomised, open-label, phase 3 trial. Lancet 2016, 387, 545-557. [CrossRef]

68. Gill, S.; Ko, Y.-J.; Cripps, C.; Beaudoin, A.; Dhesy-Thind, S.; Zulfiqar, M.; Zalewski, P.; Do, T.; Cano, P.; Han Lam, E.Y.; et al. PANCREOX: A Randomised Phase III Study of Fluorouracil/Leucovorin WITH or without Oxaliplatin for Second-Line Advanced Pancreatic Cancer in Patients Who Have Received Gemcitabine-Based Chemotherapy. J. Clin. Oncol. 2016, 34, 3914-3920. [CrossRef]

69. Pishvaian, M.J.; Blais, E.M.; Brody, J.R.; Sohal, D.; Hendifar, A.E.; Chung, V.; Mikhail, S.; Rahib, L.; Lyons, E.; Tibbetts, L.; et al. Outcomes in pancreatic adenocarcinoma (PDA) patients (pts) with genetic alterations in DNA damage repair (DDR) pathways: Results from the Know Your Tumor (KYT) program. J. Clin. Oncol. 2019, 37, 191. [CrossRef]

70. Golan, T.D.; Kanji, Z.S.; Epelbaum, R.; Devaud, N.; Dagan, E.; Holter, S.; Aderka, D.; Paluchshimon, S.; Kaufman, B.A.; Gershonibaruch, R.; et al. Overall survival and clinical characteristics of pancreatic cancer in BRCA mutation carriers. Br. J. Cancer 2014, 111, 1132-1138. [CrossRef]

71. Chiorean, E.G.; Guthrie, K.A.; Philip, P.A.; Swisher, E.M.; Jalikis, F.; Pishvaian, M.J.; Berlin, J.; Noel, M.S.; Suga, J.M.; GarridoLaguna, I.; et al. Randomized phase II study of second-line modified FOLFIRI with PARP inhibitor ABT-888 (Veliparib) (NSC-737664) versus FOLFIRI in metastatic pancreatic cancer (mPC): SWOG S1513. J. Clin. Oncol. 2019, 37, 4014. [CrossRef]

72. Glassman, D.C.; Palmaira, R.L.; Covington, C.M.; Desai, A.M.; Ku, G.Y.; Li, J.; Harding, J.J.; Varghese, A.M.; O’Reilly, E.M.; Yu, K.H. Nanoliposomal irinotecan with fluorouracil for the treatment of advanced pancreatic cancer, a single institution experience. BMC Cancer 2018, 18, 1-10. [CrossRef] [PubMed]

73. Pishvaian, M.J.; Bender, R.J.; Halverson, D.; Rahib, L.; Hendifar, A.E.; Mikhail, S.; Chung, V.; Picozzi, V.J.; Sohal, D.; Blais, E.M.; et al. Molecular Profiling of Patients with Pancreatic Cancer: Initial Results from the Know Your Tumor Initiative. Clin. Cancer Res. 2018, 24, 5018-5027. [CrossRef] [PubMed]

74. Le, D.T.; Uram, J.N.; Wang, H.; Bartlett, B.R.; Kemberling, H.; Eyring, A.D.; Skora, A.D.; Luber, B.S.; Azad, N.S.; Laheru, D.; et al. PD-1 Blockade in Tumors with Mismatch-Repair Deficiency. N. Engl. J. Med. 2015, 372, 2509-2520. [CrossRef]

75. Hu, Z.I.; Shia, J.; Stadler, Z.K.; Varghese, A.M.; Capanu, M.; Salo-Mullen, E.; Lowery, M.A.; Diaz, L.A.; Mandelker, D.; Yu, K.H.; et al. Evaluating Mismatch Repair Deficiency in Pancreatic Adenocarcinoma: Challenges and Recommendations. Clin. Cancer Res. 2018, 24, 1326-1336. [CrossRef] [PubMed]

76. Singhi, A.D.; George, B.; Greenbowe, J.R.; Chung, J.; Suh, J.; Maitra, A.; Klempner, S.; Hendifar, A.; Milind, J.M.; Golan, T.; et al. Real-Time Targeted Genome Profile Analysis of Pancreatic Ductal Adenocarcinomas Identifies Genetic Alterations That Might Be Targeted with Existing Drugs or Used as Biomarkers. Gastroenterology 2019, 156, 2242-2253.e4. [CrossRef] [PubMed] 
77. Drilon, A.; Laetsch, T.W.; Kummar, S.; DuBois, S.G.; Lassen, U.N.; Demetri, G.D.; Nathenson, M.; Doebele, R.C.; Farago, A.F.; Pappo, A.S.; et al. Efficacy of Larotrectinib in TRK Fusion-Positive Cancers in Adults and Children. N. Engl. J. Med. 2018, 378, 731-739. [CrossRef] [PubMed]

78. Demetri, G.; Paz-Ares, L.; Farago, A.; Liu, S.; Chawla, S.; Tosi, D.; Kim, E.; Blakely, C.; Krauss, J.; Sigal, D.; et al. Efficacy and safety of entrectinib in patients with NTRK fusion-positive (NTRK-fp) Tumors: Pooled analysis of STARTRK-2, STARTRK-1 and ALKA-372-001. Ann. Oncol. 2018, 29, viii713. [CrossRef]

79. Liu, S.V.; Feldman, R.; Borghaei, H.; Gadgeel, S.M.; Ma, P.C.; Nieva, J.J.; Spira, A.I.; VanderWalde, A.M.; Wozniak, A.J.; Jonna, S.; et al. Incidence of Neuregulin1 (NRG1) gene fusions across tumor types. J. Clin. Oncol. 2018, 36, 12084. [CrossRef]

80. Heining, C.; Horak, P.; Uhrig, S.; Codo, P.L.; Klink, B.; Hutter, B.; Fröhlich, M.; Bonekamp, D.; Richter, D.; Steiger, K.; et al. NRG1 Fusions in KRAS Wild-Type Pancreatic Cancer. Cancer Discov. 2018, 8, 1087-1095. [CrossRef]

81. Jones, M.R.; Williamson, L.M.; Topham, J.T.; Lee, M.K.C.; Goytain, A.; Ho, J.; Denroche, R.E.; Jang, G.-H.; Pleasance, E.D.; Shen, Y.; et al. NRG1 gene fusions are recurrent, clinically actionable gene rearrangements in KRAS wild-type pancreatic ductal adenocarcinoma. Clin. Cancer Res. 2019, 25, 4674-4681. [CrossRef]

82. Holter, S.; Borgida, A.; Dodd, A.; Grant, R.; Semotiuk, K.; Hedley, D.; Dhani, N.; Narod, S.; Akbari, M.; Moore, M.; et al. Germline BRCA Mutations in a Large Clinic-Based Cohort of Patients with Pancreatic Adenocarcinoma. J. Clin. Oncol. 2015, 33, $3124-3129$. [CrossRef]

83. Salo-Mullen, E.E.; O’Reilly, E.M.; Kelsen, D.P.; Ashraf, A.M.; Lowery, M.A.; Yu, K.h.; Reidy, D.L.; Epstein, A.S.; Lincoln, A.; Saldia, A.; et al. Identification of germline genetic mutations in patients with pancreatic cancer. Cancer 2015, 121, 4382-4388. [CrossRef]

84. Lowery, M.; Wong, W.; Jordan, E.J.; Lee, J.W.; Kemel, Y.; Vijai, J.; Mandelker, D.; Zehir, A.; Capanu, M.; Salo-Mullen, E.; et al. Prospective Evaluation of Germline Alterations in Patients with Exocrine Pancreatic Neoplasms. J. Natl. Cancer Inst. 2018, 110, 1067-1074. [CrossRef]

85. Stoffel, E.M.; McKernin, S.E.; Brand, R.; Canto, M.; Goggins, M.; Moravek, C.; Nagarajan, A.; Petersen, G.M.; Simeone, D.M.; Yurgelun, M.; et al. Evaluating Susceptibility to Pancreatic Cancer: ASCO Provisional Clinical Opinion. J. Clin. Oncol. 2019, 37, 153-164. [CrossRef] [PubMed]

86. Cremin, C.; Lee, M.; Hong, Q.; Hoeschen, C.; Kalloger, S.; Karasinska, J.; MacKenzie, A.; McCullum, M.; Nuk, J.E.; Topham, J.T.; et al. Unselected germline screening in pancreatic adenocarcinoma yields high rates of pathogenic and likely pathogenic variants (PV) in hereditary cancer susceptibility genes. J. Clin. Oncol. 2019, 37, 1582. [CrossRef]

87. Tempero, M.A.; Malafa, M.P.; Al-Hawary, M.; Behrman, S.W.; Benson, A.B.; Cardin, D.B.; Chiorean, E.G.; Chung, V.; Czito, B.; Del Chiaro, M.; et al. Pancreatic Adenocarcinoma, Version 2. 2021, NCCN Clinical Practice Guidelines in Oncology. J. Natl. Compr. Canc. Netw. 2021, 19, 439-457. [CrossRef]

88. Golan, T.; Hammel, P.; Reni, M.; Van Cutsem, E.; Macarulla, T.; Hall, M.J.; Park, J.-O.; Hochhauser, D.; Arnold, D.; Oh, D.-Y.; et al. Maintenance Olaparib for Germline BRCA-Mutated Metastatic Pancreatic Cancer. N. Engl. J. Med. 2019, 381, 317-327. [CrossRef] [PubMed]

89. Symecko, H.; Mueller, R.; Spielman, K.; Batson, M.; Pundock, S.; Hamilton, J.G.; Robson, M.E.; Domchek, S.M. Ten-fold increase in genetic testing in pancreatic and metastatic prostate cancer with implementation of point of care (POC) testing. J. Clin. Oncol. 2019, 37, 1506. [CrossRef]

90. Primrose, J.N.; Fox, R.P.; Palmer, D.H.; Malik, H.Z.; Prasad, R.; Mirza, D.; Anthony, A.; Corrie, P.; Falk, S.; Finch-Jones, M.; et al. Capecitabine compared with observation in resected biliary tract cancer (BILCAP): A randomised, controlled, multicentre, phase 3 study. Lancet Oncol. 2019, 20, 663-673. [CrossRef]

91. Nassour, I.; Mokdad, A.A.; Porembka, M.R.; Choti, M.A.; Polanco, P.M.; Mansour, J.C.; Minter, R.M.; Wang, S.C.; Yopp, A.C. Adjuvant Therapy Is Associated with Improved Survival in Resected Perihilar Cholangiocarcinoma: A Propensity Matched Study. Ann. Surg. Oncol. 2018, 25, 1193-1201. [CrossRef]

92. Valle, J.; Wasan, H.; Palmer, D.H.; Cunningham, D.; Anthoney, A.; Maraveyas, A.; Madhusudan, S.; Iveson, T.; Hughes, S.; Pereira, S.P.; et al. Cisplatin plus Gemcitabine versus Gemcitabine for Biliary Tract Cancer. N. Engl. J. Med. 2010, 362, $1273-1281$. [CrossRef]

93. Lamarca, A.; Palmer, D.H.; Wasan, H.S.; Ross, P.J.; Ting Ma, Y.; Arora, A.; Falk, S.; Gillmore, R.; Wadsley, J.; Patel, K.; et al. ABC06 I A randomised phase III, multi-centre, open-label study of Active Symptom Control (ASC) alone or ASC with oxaliplatin/5-FU chemotherapy (ASC+mFOLFOX) for patients (pts) with locally advanced/metastatic biliary tract cancers (ABC) previouslytreated with cisplatin/gemcitabine (CisGem) chemotherapy. J. Clin. Oncol. 2019, 37, 4003.

94. Kim, B.J.; Yoo, C.; Kim, K.-P.; Hyung, J.; Park, S.J.; Ryoo, B.-Y.; Chang, H.-M. Efficacy of fluoropyrimidine-based chemotherapy in patients with advanced biliary tract cancer after failure of gemcitabine plus cisplatin: Retrospective analysis of 321 patients. $\mathrm{Br}$. $\mathrm{J}$. Cancer 2017, 116, 561-567. [CrossRef]

95. Marabelle, A.; Le, D.T.; Ascierto, P.A.; Di Giacomo, A.M.; De Jesus-Acosta, A.; Delord, J.-P.; Geva, R.; Gottfried, M.; Penel, N.; Hansen, A.R.; et al. Efficacy of Pembrolizumab in Patients with Noncolorectal High Microsatellite Instability/Mismatch Repair-Deficient Cancer: Results From the Phase II KEYNOTE-158 Study. J. Clin. Oncol. 2020, 38, 1-10. [CrossRef]

96. Graham, R.; Fritcher, E.G.B.; Pestova, K.; Schulz, J.; Sitailo, L.A.; Vasmatzis, G.; Murphy, S.J.; McWilliams, R.R.; Hart, S.; Halling, K.C.; et al. Fibroblast growth factor receptor 2 translocations in intrahepatic cholangiocarcinoma. Hum. Pathol. 2014, 45, 1630-1638. [CrossRef] [PubMed] 
97. Abou-Alfa, G.K.; Sahai, V.; Hollebecque, A.; Vaccaro, G.; Melisi, D.; Al-Rajabi, R.; Paulson, A.S.; Borad, M.J.; Gallinson, D.; Murphy, A.G.; et al. Pemigatinib for previously treated, locally advanced or metastatic cholangiocarcinoma: A multicentre, open-label, phase 2 study. Lancet Oncol. 2020, 21, 671-684. [CrossRef]

98. Javle, M.M.; Roychowdhury, S.; Kelley, R.K.; Sadeghi, S.; Macarulla, T.; Waldschmidt, D.T.; Goyal, L.; Borbath, I.; El-Khoueiry, A.B.; Yong, W.-P.; et al. Final results from a phase II study of infigratinib (BGJ398), an FGFR-selective tyrosine kinase inhibitor, in patients with previously treated advanced cholangiocarcinoma harboring an FGFR2 gene fusion or rearrangement (abstract). J. Clin. Oncol. 2021, 39, 265. [CrossRef]

99. Mosele, F.; Remon, J.; Mateo, J.; Westphalen, C.; Barlesi, F.; Lolkema, M.; Normanno, N.; Scarpa, A.; Robson, M.; Meric-Bernstam, F.; et al. Recommendations for the use of next-generation sequencing (NGS) for patients with metastatic cancers: A report from the ESMO Precision Medicine Working Group. Ann. Oncol. 2020, 31, 1491-1505. [CrossRef] [PubMed] 